\title{
Comparative Flow Path Analysis and Design Assessment of an Axisymmetric Hydrogen Fueled Scramjet Flight Test Engine at a Mach Number of 6.5
}

\author{
C. McClinton*; NASA LaRC, Hampton, Va., USA
}

A. Roudakov**, V. Semenov ***, and V. Kopehenov***; CIAM, Moscow, Russia

\begin{tabular}{|c|c|c|c|}
\hline & Abstract & $P_{G 1}$ & Combustor pressure for ramjet \\
\hline $\begin{array}{l}\text { NAS } \\
\text { of } A\end{array}$ & $\begin{array}{l}\text { has contracted with the Central Institute } \\
\text { tion Motors CIAM to perform a flight }\end{array}$ & $P_{G 2}$ & $\begin{array}{l}\text { Combustor pressure for scramjet } \\
\text { (stage I) fuel control. }\end{array}$ \\
\hline $\begin{array}{l}\text { test a } \\
\text { engir }\end{array}$ & ground test and provide a scramjet & Q & Flight dynamic pressure, $\mathrm{kPa}$ \\
\hline objec & for ground test in the United States. Ine & qavg & $\begin{array}{l}\text { Laterally averaged combustor } \\
\text { heat flux, } \mathrm{W} / \mathrm{m}^{2}\end{array}$ \\
\hline $\begin{array}{l}\text { fligh1 } \\
\text { ramje }\end{array}$ & $\begin{array}{l}\text { orrelation for a supersonic combustion } \\
\text { (scramjet) engine operating point at a }\end{array}$ & qpeak & Peak heat flux, $\mathrm{W} / \mathrm{m}^{2}$ \\
\hline Macl & umber of 6.5 . This paper presents results & $\mathrm{R}, \mathrm{m}$ & Radial coordinate \\
\hline from & flow path performance and thermal & $\mathrm{t}$ & Time \\
\hline evalu & ion performed on the design proposed by & $\mathrm{T}_{\mathrm{W}}$ & Wall temperature \\
\hline $\begin{array}{l}\text { the } C \\
\text { perfo } \\
\text { oper: }\end{array}$ & $\begin{array}{l}\text { M. This study shows that the engine will } \\
\text { in the scramjet mode for stoichiometric } \\
\text { on at a flight Mach number of } 6.5 \text {. }\end{array}$ & $\mathrm{T}_{\mathrm{W}, \max }$ & $\begin{array}{l}\text { Maximum combustor wall } \\
\text { temperature from thermal } \\
\text { analysis, } K\end{array}$ \\
\hline $\begin{array}{l}\text { Ther } \\
\text { that t }\end{array}$ & $\begin{array}{l}\text { assessment of the structure indicates } \\
\text { combustor cooling liner will provide }\end{array}$ & $\mathrm{T}_{\text {crit }}$ & $\begin{array}{l}\text { Critical combustor wall } \\
\text { temperature units }\end{array}$ \\
\hline $\begin{array}{l}\text { adeq } \\
\text { cond }\end{array}$ & $\begin{array}{l}\text { te cooling for a Mach number of } 6.5 \text { test } \\
\text { on and that optional material proposed by }\end{array}$ & $\mathrm{T}_{2}$ & Inlet throat temperature \\
\hline CIAI & $\begin{array}{l}\text { for the cowl leading-edge design are } \\
d \text { to allow operation with or without a }\end{array}$ & w & $\begin{array}{l}\text { Combustor segment width, } \\
\text { degrees (figure 2) }\end{array}$ \\
\hline type & shock-shock interaction. & $\begin{array}{l}\mathrm{x} \\
\varepsilon\end{array}$ & $\begin{array}{l}\text { Axial distance from inlet tip, meters } \\
\text { Total, hemispherical emissivity }\end{array}$ \\
\hline & Symbol List & $\eta_{\mathrm{KE}, 1}$ & Inlet kinetic energy efficiency of \\
\hline & $\begin{array}{l}\text { Heat capacity }(\mathrm{j} / \mathrm{kg} / \mathrm{K}) \\
\text { Fuel injector diameter, } \mathrm{mm}\end{array}$ & $\eta_{\mathrm{KE}, 2}$ & $\begin{array}{l}\text { cowl lip plane } \\
\text { Inlet kinetic energy efficiency of }\end{array}$ \\
\hline $\begin{array}{l}E \\
E_{b}\end{array}$ & $\begin{array}{l}\text { Radiation heat transfer } \\
\text { Radiation from a black body }\end{array}$ & $\eta_{\mathrm{KE}, \text { Adia., } 1}$ & $\begin{array}{l}\text { throat station } \\
\text { Inlet adiabatic kinetic energy }\end{array}$ \\
\hline $\begin{array}{l}\mathrm{h} \\
\mathrm{L} / \mathrm{H}\end{array}$ & $\begin{array}{l}\text { Altitude, meters } \\
\text { Inlet isolator length } \mathrm{L} \text { to height } \mathrm{H} \text { ratio }\end{array}$ & $\eta_{\mathrm{KE} \text { Adia } 2}$ & $\begin{array}{l}\text { efficiency of cowl lip plane } \\
\text { Inlet kinetic energy efficiency }\end{array}$ \\
\hline $\mathrm{m}$ & Engine mass capture, $\mathrm{kg} / \mathrm{sec}$ & & of throat station \\
\hline & $\begin{array}{l}\text { Flight Mach number } \\
\text { Inlet throat Mach number }\end{array}$ & $\theta_{w}$ & $\begin{array}{l}\text { Combustor wall divergence } \\
\text { angle, degrees }\end{array}$ \\
\hline$P_{0}^{\prime}$ & Free stream, cone pitot pressure & $\lambda$ & Thermal conductivity, $w / \mathrm{m} / \mathrm{K}$ \\
\hline $\mathrm{P}_{1}$ & $\begin{array}{l}\text { 1st Inlet cone pressure (used to est. } \\
\text { flight } \mathrm{Mach}) \mathrm{Pa}\end{array}$ & $\begin{array}{l}\rho \\
\phi_{c}\end{array}$ & $\begin{array}{l}\text { Density, } \mathrm{kg} / \mathrm{m}^{3} \\
\text { Reacted fuel equivalence ratio }\end{array}$ \\
\hline $\mathrm{P}_{2}$ & Inlet throat pressure, $\mathrm{Pa}$ & $\begin{array}{l}\phi \\
\phi_{\text {cool }}\end{array}$ & $\begin{array}{l}\text { Fuel equivalence ratio } \\
\text { Cooling flow rate in terms of fuel }\end{array}$ \\
\hline $\mathrm{P}_{4}$ & $\begin{array}{l}\text { Forebody cone pressure, third cone } \\
\text { section ahead of cowl lip }\end{array}$ & $\Phi$ & $\begin{array}{l}\text { equivalence ratio } \\
\text { Diameter }\end{array}$ \\
\hline $\mathrm{P}_{5}$ & $\begin{array}{l}\text { Inlet body-side pressure, third cone } \\
\text { section downstream of cowl lip }\end{array}$ & I, II, III & Injector stages \\
\hline $\begin{array}{ll}* & N \\
* * & C \\
* * * & I\end{array}$ & $\begin{array}{l}\text { ager, Numerical Applications Office, Member } \\
\text {, Aerospace Propulsion Department } \\
\text { aty Chief, Aerospace Propulsion Department }\end{array}$ & & \\
\hline $\begin{array}{l}\text { Cop } \\
\text { Uni }\end{array}$ & $\begin{array}{l}\text { (0) } 1991 \text { by the American Institute of Aeron } \\
\text { es under Title } 17, \text { U. S. Code. The U. S. G } \\
\text { ht claimed herein for Governmental purpo }\end{array}$ & & $\begin{array}{l}\text { the } \\
\text { s under }\end{array}$ \\
\hline
\end{tabular}

$P_{G 1}$

$\mathrm{P}_{\mathrm{G} 2}$

Q

qavg

qpeak

$\mathrm{R}, \mathrm{m}$

$T_{W}$

$\mathrm{T}_{\mathrm{W}, \max }$

$\mathrm{T}_{\text {crit }}$

$\mathrm{T}_{2}$

$\mathrm{x}$

$\varepsilon$

$\eta_{K E}$

$\eta_{\mathrm{KE}, \mathrm{Adia}, \text {,2 }}$

$\theta_{\mathrm{w}}$

$\lambda$

$\phi_{\mathrm{C}}$

$\phi_{\text {cool }}$

$\Phi$

I, II, II
Combustor pressure for ramjet Combustor pressure for scramjet (stage I) fuel control. heat flux, W/m $/ \mathrm{m}^{2}$ Radial coordinate Time Maximum combustor wall temperature from thermal Critical combustor wall temperature units Combustor segment width, degrees (figure 2) Total, hemispherical emissivity Inlet kinetic energy efficiency of cowl lip plane throat station Inlet adiabatic kinetic energy efficiency of cowl lip plane of throat station angle, degrees Thermal conductivity, $w / m / K$ Density, $\mathrm{kg} / \mathrm{m}^{3}$

Fuel equivalence ratio Cooling flow rate in terms of fue equivalence ratio Diameter njector stages 


\section{Introduction}

NASA contracted with the Central Institute of Aviation Motors CLAM to perform a flight test of an axisymmetric scramjet designed by CIAM using the Hypersonic Flying Laboratory (HFTB) (ref. 1). Previous scramjet engine flight data have been obtained by Russian flight tests at a Mach number of 5.35 (ref. 1) and by a French and Russian flight test at about a Mach number of 6 (ref. 2). The NASA contract provides for ground and flight tests at a Mach number of 6.5 for a modified axisymmetric design. The contract calls for 4 engines, two for ground testing, one for flight testing, and one backup for flight testing. The first ground test will be performed by CIAM in the CIAM C-16V/K facility at Tureavo. The tests performed by NASA will be postflight tests, and duplicate the flight conditions. The overall program will provide ground-to-flight and facility-to-facility comparisons.

Two scramjet engine test articles were designed for the NASA flight test. The design for a Mach number of 7 is reported in reference 4 and the preliminary design for flight at a Mach number of 6.5 in reference 5 . Several changes were initially incorporated in these designs, such as expanding combustor sections to assure scramjet operation and improved combustor cooling liner designs. Subsequently, the cooling liner material was changed from steel to a copper-based alloy, the liner extended into the inlet isolator, and a new material selected for the inlet cowl leading edge.

Work reported herein presents the status of a detailed analysis of the scramjet engine 58 design. This work includes inlet and combustor flow path and thermal analysis by a combination of methods. The objective of this analysis is to ensure that combustion is supersonic at the design operating point and that the flow path and external structure will survive the flight test.

Results presented are not complete; however, the results illustrate the analysis approach and demonstrate the expected performance and some structural design issues.

\section{Experimental Apparatus and Test Conditions}

The scramjet engine, illustrated in figure 1 includes an axisymmetric internal-external mixed-compression, Mach number 6 design shock-on-lip inlet, a short $(\mathrm{L} / \mathrm{H}=6)$ isolator, three fuel injection stages (including two cavity flame holders), an expanding combustor, and partial nozzle (on the cowl side only). The inlet incorporates a 6-mm diameter pitot tube, a 10 degree initial half angle conical center body followed by two additional 5 degree compression "conical sections". The cowl lip incorporates a $0.5-\mathrm{mm}$ radius leading edge with the external surface inclined 24 degrees to the model centerline and the internal surface inclined 10 degrees. Internal contraction rather is only 1.33 for this configuration, which has been shown to start at about a Mach number of 3.5 in previous tests (ref. 1). The internal inlet utilizes 3 body-side expansion and 2 cowl-side compression turns to return the flow parallel to the scramjet centerline. Three pylon spacers are included in the isolator section to position the cowl. These pylons are welded only on the body side.

The combustor includes three fuel injector stations, two with cavity flame holder $(20 \mathrm{~mm}$ by $40 \mathrm{~mm}$ and $30 \mathrm{~mm}$ by $53 \mathrm{~mm}$ ) and one with a step (17 mm) flame holder. Ignition is provided by two spark plugs in cavity III and two located downstream of the step flame holder at injector station II, which are continually active during the flight test. In all cases, sonic flush-wall fuel injection is either from the aft-facing step (injected at 30 degrees to the engine axis) or just upstream of the step at 45 degrees. Fuel injectors at stations II and III are for ramjet and scramjet operation and station I is utilized only in scramjet operation. The flow path details, shown in figure 1(b), include a small expansion ( 0.95 degrees) in the upstream combustor, a $17-\mathrm{mm}$ step into the downstream combustor, which includes a 2.89-degree expanding section that is followed by an essentially constant area section. The last expansion (4.84 degrees) in the combustor provides area relief for the $4 \mathrm{aft}$ pylons.

\section{Structure and Materials}

This redesigned shock-on-lip engine with a design Mach number of 6 shares much of the structural design with previous flight test engines designed by CIAM. The major difference is in the cooling passage (channel) layout of the combustor liner. The current design was provided by the ChemAutomatics Design Bureau.

Structural and material details are illustrated in figure 2 . The nose of the inlet center body 
includes a 6-mm diameter pitot tube in the tip (with blunt edge resulting in a 7-mm diameter at the tangent point to the first conical section). The nose cone extends back to the $90-\mathrm{mm}$ station and is constructed from EP666 high-temperature steel (1100 K design limit with short excursions to $1400 \mathrm{~K}$ design limit). Detailed properties of this material are provided in table 1 . Aft of the nose tip, most of the center body wall is made of 3-mm thick 12X18H10T low-temperature steel, which has a design limit of $900 \mathrm{~K}$. Wall thickness increases at the third conical compression surface (335-mm station) and can be modeled as 12.52 -mm thick, which is the minimum thickness to the stage I fuel injector manifold. The entire external center body is coated with a chromium-nickel $(\mathrm{CrNi})$ spray to increase the total, hemispherical emissivity $(\varepsilon)$ to 0.9. This emissivity is defined by $\varepsilon=\mathrm{E} / \mathrm{E}_{\mathrm{b}}$, where $E$ is radiation heat transfer and $E_{b}$ is the radiation from a black body at the same temperature. The cowl leading edge is constructed from PM-25-10L powered metal matrix composite material and the outer cowl protective cover, which is $1.5-\mathrm{mm}$ thick (figure 2), is constructed from EP666 hightemperature steel. As with the center body, this section is covered with radiation enhancing $\mathrm{CrNi}$ coating. The PM-25-10L material has about the same conductivity, but nearly twice the hightemperature heat capacity as the EP666 steel and a short excursion peak temperature limit of $1773 \mathrm{~K}$, which is nearly $300 \mathrm{~K}$ higher than that for the EP666 steel.

The inner cowl surface aft of the cowl lip is covered with the cooled heat exchanger. The three inlet spacer pylons, made from uncoated EP666 steel, are welded to the center body structure and press against the internal cowl wall. These pylons are identical to previous pylons, which exhibited only small erosion in the first Russian flight test at Mach numbers to 5.35.

The entire combustor is hydrogen fueled and is regeneratively cooled with a liner. The extent of the liner is shown in figure 2 and typical liner cross sections are shown in figure 3 . Two designs were proposed by CIAM: an all steel design and a copper and steel design. The copper and steel design was selected by CIAM. The liner is made from a combination of copper alloy (800 $\mathrm{K}$ design temperature limit), referred to as bpXUpT and high temperature steel alloy EP666. Most of the hot side is constructed from the copper alloy and all the cold side is constructed from steel. Figure 3 illustrates a cross section of the liner heat exchanger and shows the copper and steel components. The $2 \mathrm{~mm}$ by $2 \mathrm{~mm}$ cooling channels which run parallel to the air flow direction, are machined into the copper (hot) side and the steel back plate is silver soldered to the copper face plate. This copper and steel construction is used for most of the combustor except: (1) the instrumentation rings, (2) the back face and bottom face of the flame holding cavities, and (3) the combustor exit-nozzle section aft of the aft pylon leading edge. These sections are all constructed from steel. Separate cooling passages are created in the instrumentation rings to accommodate 10-mm diameter instrumentation plugs because instrumentation blocks some of the coolant flow passages. The $10-\mathrm{mm}$ long instrumentation rings are bounded by a $5-\mathrm{mm}$ long axial ring section composed of 2 steel rings, which are brazed between the face and back sheets. This construction provides a 360 degree wrap manifold to redistribute the coolant flow around the instrumentation blockages. Because the original design proposed either copper or steel for the hot side of the heat exchanger, both heat exchangers were evaluated.

The aft pylon contains fuel cooling transfer tubes, instrumentation lines, and cowl (stage II) fuel lines and anchors the cowl to the center body. Three tubes are contained within each pylon and are electron beam welded to the center body and cowl cooling panels. The tubes are covered with a thin welded cover, and finally with a thick aerodynamic layer of Niobium. This final piece is epoxied at both ends rather than welded to control hot gas leaks in the structure. The pylon leading edge is coated with about $1.6 \mathrm{~mm}$ of $\mathrm{SiO}_{2}$ to provide oxidation protection for the Niobium.

\section{Fuel and Cooling Control System}

Fuel and coolant flow is controlled by a pneumatic system that is illustrated in figure 4 . This figure shows the location of measurements used in the control logic, as well as the control valves for the fuel and coolant flow. Fuel control requires determination of flight Mach number (estimated using $\mathrm{P}_{0}{ }^{\prime} / \mathrm{P}_{4}$ ), inlet start/unstart $\left(\mathrm{P}_{5} / \mathrm{P}_{4}\right)$, and monitoring and comparing the combustor pressure with design levels. For ramjet operation, control of fuel at stages II and III is achieved using the pressure ratio $P_{G 1} / P_{4}$. For scramjet operation, the ramjet fuel control described above is utilized, plus fuel at stage $\mathrm{I}$ is controlled by $\mathrm{P}_{\mathrm{G} 2} / \mathrm{P}_{4}$. 
The coolant and fuel flow are not turned on until the inlet starts. Inlet start is detected by $\mathrm{P}_{5}<\mathrm{P}_{4}$. Upon inlet start (generally at about a Mach number of 3.5), valve KR-1/2 opens fully and provides fuel flow to the cooling system and pressure to the fuel manifolds. The pressure available for fuel injection depends on cooling system pressure losses, which depend on coolant flow rate. If the critical combustor wall temperature ( $\left.T_{\text {crit }}\right)$ does not exceed a predetermined value, the coolant flow is equal to the fuel injection flow rate. The previous tests have used $850 \mathrm{~K}$ as the critical temperature with measurements taken on both the cowl and the center body just downstream of the stage II injectors. If the critical temperature is exceeded, the coolant flow is increased by opening the fuel dump valve $\mathrm{KR}-4$. For the engine designed for a Mach number of 6.5, the design fuel dump flow rate is $0.130 \mathrm{~kg} / \mathrm{sec}$. For operation at a Mach number of 6.5 and an altitude of $26 \mathrm{~km}$, this flow dump rate represents a fuel equivalence ratio of about 1.75 .

To determine the desired fuel flow rate, the flight Mach number is calculated, then this Mach number is used to establish the target combustor pressures. If this target pressure value is not matched, valve Z-1A and/or Z-2A are opened or closed slowly until the pressure ratio is in agreement $(+/-10$ percent) with the target value. Inlet unstart is also monitored. If the inlet unstarts, which is determined by $\mathrm{P}_{5}>\mathrm{P}_{4}$, then the fuel dump valve KR-4 opens fully to assure good cooling (possibly also reducing the fuel flow rate) and simultaneously, the control valves Z-1A and/or Z-2A are gradually closed until the inlet restarts. When the inlet restarts, the controls then revert to normal operation.

\section{Flight Trajectory}

Flight trajectory details, which include altitude, dynamic pressure, and Mach number as a function of time, are illustrated in figure 5. Inlet start and ramjet operation commence at a Mach number of 3.5 , which is about $35 \mathrm{sec}$ into the flight. The design test condition point of Mach number 6.5 is achieved at $58 \mathrm{sec}$. Note that the dynamic pressure is relatively constant (about $65 \mathrm{kPa}$, or $1350 \mathrm{psf}$ ) through this 25 -sec portion of the flight. The current flight test plan calls for $5 \mathrm{sec}$ of scramjet operation after a Mach number of 6.5 is achieved.

\section{Analytical Methods}

\section{Flow Path Performance}

Performance evaluation of the scramjet flight article inlet and combustor designed by CIAM for a Mach number of 6.5 was accomplished with a combination of numerical, analytical, and empirical methods, which are illustrated in figure 6. This study was performed assuming a Mach number of 6.5 at an altitude of $26 \mathrm{~km}$ with stoichiometric combustor operation and fuel split $0.25,0.375$ and 0.375 between injector stations I, II, and III respectively. Fuel injection occupied at $560 \mathrm{kPa}$ and $950 \mathrm{~K}$ total pressure and temperature, respectively. Uniform wall temperature was initially assumed to be $1200 \mathrm{~K}$ for the entire engine, but some sections have been re-analyzed with wall temperatures provided by the thermal analysis.

Inlet analysis was performed with an in-house Reynolds average Navier Stokes solver by CIAM (ref. 5) and with the GASP code (ref. 6) by NASA. Both solutions were performed in the axisymmetric mode. The former was performed with blunt center body, sharp cowl, and fully turbulent flow; the latter accounted for both nose and cowl bluntness, as well as boundary layer transition. The external inlet solution was continued both internal and over the external cowl forward facing surface. The internal inlet solution with GASP was used as the inflow for the combustor analysis. The combustor flow was evaluated using both the SHIP three-dimensional Parabolized Navier Stokes code and the GASP code. GASP solutions, axisymmetric and threedimensional, were utilized to evaluate autoignition, performance of the stage I fuel injectors; SHIP was used to model the overall combustor performance and wall loads. The combustor analysis was performed with a threedimensional slice approach, as illustrated in figure 1(b). This three-dimensional symmetrical slice represents 4.29 degrees of the annular combustor and is thus treated as being rectangular to simplify the analyses. Note that the analysis with SHIP was performed without modeling the cavity flame holders. However, the final solution from SHIP utilized wall temperature distributions provided by the thermal analysis. The combustor performance was also estimated with empirical combustion efficiency relations that were derived from previous tests (ref. 5). 


\section{Thermal Analysis}

Thermal analysis was performed both by NASA and by DBCA, Voronezh (ref. 5). The results presented herein were generated with a method developed by NASA to interface SHIP and GASP heat loads with a one-dimensional convection model and a two-dimensional finite difference conduction model for the combustor liner. A more complex finite element analysis was employed for evaluation of threedimensional effects in the combustor and the flame holder cavity. The cowl leading-edge analysis was performed by using a transient, axisymmetric, finite element model and heat loads from the GASP solutions at various wall temperatures. Shock-on-lip analysis was performed with both steady and unsteady approximations of the shock-shock interactions. (Comparisons between results from the analysis by NASA and CIAM (ref. 3) are underway).

\section{Flow Path Performance Predictions}

Unless otherwise indicated, these results are for a Mach number of 6.5 and an altitude of $26 \mathrm{~km}$.

Inlet

Results from the inlet analysis at a Mach number of 6.5 that was performed by CIAM (ref. 5) are presented in figure 7(a), and those from the NASA analysis are presented in figure 7(b). Note that for both solutions, the three-shock waves coalesce before the cowl leading edge and are captured by the inlet. These shocks cause a small separated region on the cowl just inside the internal inlet and a larger separated region on the body side, at the $0.49-\mathrm{m}$ station. These regions are relatively small $(0.012$ - and $0.022-\mathrm{m}$ long, respectively) and should allow stable inlet operation, albeit with some performance degradation. The center-body-side separated region does not extend out of the constant area isolator section for either solution. Inlet performance at a Mach number of 6.5 , an altitude of $26 \mathrm{~km}$, and an angle of attack of 0 degrees is presented in table 2. The CIAM and NASA predictions show good agreement. Predicted heat fluxes for the external inlet decrease rapidly from $375 \mathrm{~W} / \mathrm{cm}^{2}$ at the center body tip to $8 \mathrm{~W} / \mathrm{cm}^{2}$ just upstream of the first compression corner. Following boundary layer transition, the heat flux jumps to about

$70 \mathrm{~W} / \mathrm{cm}^{2}$ over the third compression section. The cowl leading edge heat flux, even for this over speed design, reaches $600 \mathrm{~W} / \mathrm{cm}^{2}$, but the internal inlet heat flux averages about 80 to $100 \mathrm{~W} / \mathrm{cm}^{2}$ with a peak value of $175 \mathrm{~W} / \mathrm{cm}^{2}$ at the center body separation region reattachment point $(0.493-\mathrm{m}$ station, figure $7(\mathrm{~b}))$. The external cowl surface, which features 24 degrees of compression, has an average heat flux of about $40 \mathrm{~W} / \mathrm{cm}^{2}$ if the boundary layer remains laminar. However the heat flux is strongly dependent on the boundary layer state. The boundary layer should remain laminar, but even slight warpage of the cowl lip can cause premature transition (ref. 8). The effect of transition on surface temperature for the cowl lip and external cover are discussed in the "Cowl Leading Edge" section.

Parametric inlet analysis was also performed to determine flight conditions which produce center body shock impingement on the cowl leading edge. These studies show that the inlet remains fully over-sped with an angle of attack up to 2 degrees (maximum expected - see ref. 5) at the design test point of Mach number 6.5. However, shock impingement heating, including type IV shock-shock interactions occur during the ascent through the Mach number of 6 (fractions of a second to one second exposure) and as the engine gradually slows down to a Mach number of 6 , and remains at that condition for up to 20-sec, albeit at lower dynamic pressure. Detailed evaluations of the Mach number 7 CIAM design, ref. 4, demonstrated an amplification factor of 6.5 (ratio of peak heating to stagnation point heat transfer), covering about $0.1 \mathrm{~mm}$ of the cowl lip, occurs for a type IV shock-shock interaction.

\section{Combustor}

Results determined by SHIP three-dimensional PNS solution are illustrated in figure 8. These results show that fuel mixing depends on wall temperature for this combustor (large wetted area). With the variable temperature distribution provided by iteration with the thermal analysis, the mixing efficiency (ref. 9) reaches about 87 percent at the combustor exit. This value of mixing compares favorably with the empirical combustion efficiency value of 0.80 from reference 5 . Also shown in figure 5 are results from the Navier Stokes solution determined by GASP for the upstream cavity. These results indicate more rapid mixing associated with the cavity.

The average (mass, momentum, and energy conservation based) Mach number decreases 
linearly though the combustor to about 1.5 at a $0.969-\mathrm{m}$ station at the end of the 2.89 degree expansion section. Even with more rapid combustion, which is expected when the cavities are included in the analysis, the average combustor Mach number remains supersonic.

Combustor heat flux is shock dominated due to the supersonic flow field. High peak values in the upstream portion of the combustor (between fuel injector stations I and II) are 3-dimensional. That is, wall heat flux varies rapidly up and downstream, as well as cross stream. This variance can be seen by the large difference in peak and laterally averaged heat flux distributions presented in figure 9 . The highest heat flux occurs near fuel injector station I and exceeds $230 \mathrm{~W} / \mathrm{cm}^{2}$. The highest laterally averaged heat flux occurs at the $0.82-\mathrm{m}$ station on the cowl side. At this station, the peak value is $200 \mathrm{~W} / \mathrm{cm}^{2}$ and the average value is $155 \mathrm{~W} / \mathrm{cm}^{2}$. Results presented in figure 9 utilized the wall temperature distribution determined from the two-dimensional thermal analysis with coolant flow rate equal to the fuel injection flow rate. The resultant temperature distribution utilized in the SHIP code is illustrated in figure 10 . Note that the body-side surface temperature near the inlet throat is the highest because it is at the end of the cooling passage. However, the surface temperature remains within the design limit $(1100 \mathrm{~K})$ for the stainless steel heat exchanger.

\section{Flame Holding Cavity}

Water mass fraction for a single injector in the upstream cavity flame holder is illustrated in figure 11. As mentioned previously, the cavity enhances fuel mixing. This study shows that 60 percent of the injected fuel reacted within the cavity $\left(\phi_{c}=0.15\right)$. Autoignition and flame holding within the cavity flame holders is likely at a Mach number of 6.5 , even without the spark plugs. Autoignition occurred easily with the GASP solution. Without the cavity, autoignition and flame holding is unlikely, based on reference 10 and 11 , due to the small scale $\left(d_{j} \approx 1.25 \mathrm{~mm}\right)$ and low pressure $\left(\mathrm{p}_{2} \sim 0.4 \mathrm{~atm}\right)$ of the design point.

The solution from GASP also shows that pressure rise does not move upstream of the isolator cavity for the condition $(\phi=0.25)$ evaluated at a flight Mach number of 6.5. Also, the three-dimensional solution from GASP demonstrates unsteady characteristics of the flame holder. Combustion is continuous but unsteady and the reflected shock structure moves fore and aft on the cowl surface.

\section{Thermal Predictions}

Thermal analysis was performed for both stainless-steel- and copper-faced combustor heat exchangers.

Steady-state combustor heat exchanger performance was evaluated at three levels of both average and peak heat flux (for $\mathrm{T}_{\mathrm{W}}=300 \mathrm{~K}, 675 \mathrm{~K}$ and $1200 \mathrm{~K}$ ) and three levels of fuel coolant flow rate $(\phi=1,2$ and 3$)$ for both stainless steel and copper heat exchangers. The temperature of interest for this analysis is the peak heat exchanger material (hot side surface) temperature. Figure 12 illustrates typical wall and fluid temperatures for a segment of a stainless steel heat exchanger operating with $\phi_{\text {cool }}=1.0$ with both average and peak heat flux from the SHIP code, which is applied uniformly without consideration for lateral convection. This segment is on the body side and extends from the stage I injector to the aft struts. This section is situated at the end of the cooling circuit and has the highest temperature (figure 10). Note that using axial distribution of peak heat flux results in local temperature in excess of the design temperature.

The upstream three-dimensional cavity-flameholder cooling liner design was evaluated using GASP predicted heat flux and coolant (hydrogen) outflow temperature from the above analysis (figure 12), and was determined to be the limiting condition within the cooling liner design. Figure 13(a) illustrated that at $\phi_{\text {cool }}=1.0$, the peak cavity temperature exceeds $1350 \mathrm{~K}$, compared to $1180 \mathrm{~K}$ for the remainder of the liner (as illustrated in figure 12). The effect of coolant flow rate is also illustrated in figure 13(a) and 13(b). Maximum wall temperature within the coolant liner drops within the design limit with $\phi_{\text {cool }} \approx 1.8$. Also, the coolant outflow temperature (figure $13 \mathrm{~b}$ ) drops rapidly with coolant flow rate, from $800 \mathrm{~K}$ at $\phi_{\text {cool }}=1.0$ to about 550 at $\phi_{\text {cool }}=1.8$.

Due to the nature of the fuel/coolant control system, the operating fuel equivalence ratio is uncertain. However, the information presented in figures 12,13(a), and 13(b) may be used to estimate potential operating conditions. For example, if the combustor target pressures are 
satisfied with $\phi=1.0$, and $T_{\text {crit }}$ measured is less than the target value (due to shock structure near station $0.7 \mathrm{~m}$ ) the flame holding cavity cooling liner will exceed the material temperature limits. If the critical temperature limit $\mathrm{T}_{\text {crit }}$ is met, the dump valve opens, and provides $\phi_{\text {cool }}=2.85$. Then the structure will be within design limits and the fuel temperature will drop to about $375 \mathrm{~K}$. Similar results were obtained for the copper-faced heat exchanger that is illustrated in figure 3. Because of trade-off between conductivity and limit temperature, the only differences observed were a slight increase in the required operating fuel flow rate to remain within design limits and a slight increase in fuel temperature that is illustrated in figure 13 (b). (Coolant total pressure losses are $0.299 \mathrm{mPa}$, $0.86 \mathrm{mPa}$, and $1.614 \mathrm{mPa}$ for $\phi_{\mathrm{cool}}=1,2$, and 3 , respectively). The copper-faced heat exchanger was select because of improved conductivity, which can reduce the impact of peak heating that is associated with strong shock waves.

\section{Cowl Leading Edge}

Finite element thermal analysis of the cowl leading edge, including the entire forward-facing exterior surface, was performed assuming $15 \mathrm{sec}$ exposure at a Mach number of 6.5. The CFD solutions at a Mach number of 6.5 , at an altitude of $26 \mathrm{~km}$, a Mach number of 5.5 , at an altitude $22.5 \mathrm{~km}$, and a Mach number of 6.0 , at an altitude of $35 \mathrm{~km}$ (10 sec along the flight trajectory leading to the design point of a Mach number of 6.5) show only 20 percent variation in predicted heat flux, excluding the shock-on-lip effects. This analysis was performed for both the original EP666 high-temperature-steel design and the design that uses PM-25-10L powered metal matrix composite material.

Material temperatures for the EP666 hightemperature steel for the entire cowl structure after $15 \mathrm{sec}$ of exposure to a flow at a Mach number of 6.5 , with a turbulent boundary is illustrated in figure 14. External surface temperature after $15 \mathrm{sec}$ for the laminar and turbulent solutions are illustrated in figure 16. For this condition, most of the structure has exceeded the thermal limit. The primary exception is the most massive part of the tip section. Most of the thin exterior cover has exceeded the design temperature limit $(1100 \mathrm{~K})$ for the turbulent flow solution. One third of the high-temperature steel cowl leadingedge section exceeds the design temperature limit. The cowl leading-edge tip $(0.429 \mathrm{~m})$ required less than $1 \mathrm{sec}$ of exposure to reach $1100 \mathrm{~K}$, the $0.432-\mathrm{m}$ station required approximately $1.5 \mathrm{sec}$ of exposure to reach $1100 \mathrm{~K}$, and the forward $6 \mathrm{~cm}$ exceed the short excursion temperature limit of $1400 \mathrm{~K}$.

Thermal analysis was performed for the PM-25-10L powered metal matrix composite material. Due to the higher heat capacity of this material, the peak temperature drops from $1660 \mathrm{~K}$ (figure 15) to $1600 \mathrm{~K}$ (figure 16), which is well within the design short excursion temperature limit of $1773 \mathrm{~K}$. This material assures survival of the cowl lip, which will help maintain laminar flow over the exterior cover plate and correct the inlet exterior cowl heating issues. (A failure of this section could be catastrophic as it would expose the uncooled cowl interior to hot gases.)

Center body shock impingement heating of the cowl lip can occur over a significant range of Mach numbers, due to angle-of-attack effects and will, of course, be more severe if it occurs at higher flight Mach numbers and dynamic pressures. An initial study of the conditions at a Mach number of 6.0 with shock on lip shows a very rapid rise in the cowl temperature, which exceeds $1800 \mathrm{~K}$ within $0.5 \mathrm{sec}$ for the EP666 steel. This solution used an amplification factor that was determined from the original design for a Mach number of 7 on the peak heat flux that was determined for the Mach number of 6.5. The type IV interaction peak extended over about a $0.1-\mathrm{mm}$ width that was centered 25 degrees below the no-shock stagnation point. Additional studies with the PM-25-10L powered-metal-matrix composite of both the steady state and a conservative estimate of the unsteady type IV interaction (by doubling the oversped full nose tip heat flux) show that after $0.5 \mathrm{sec}$, the peak temperature is $1725 \mathrm{~K}$ and $1675 \mathrm{~K}$ respectively. These values are both within the short excursion temperature limit of $1773 \mathrm{~K}$ (figure 16).

\section{Conclusions}

The scramjet combustor will operate in scramjet mode at a Mach number of 6.5 , with stoichiometric fueling. However, the flight condition will be established based on combustor pressure, not directly on the overall fuel to air ratio.

Mixing is affected by combustor wall temperature. 
Local mixing is significantly enhanced by flame holding cavity flame holders.

Cavity flame holders are quite effective as autoignition and flame holding devices.

Fuel temperature will be relatively cool at a Mach number of 6.5 , due to cooling requirements.

Thermal analysis confirms the new combustor cooling liner design and indicates that the critical temperature measurement must be made in the stage I flame holder.

Thermal analysis of the cowl leading edge indicates severe limitations with the original EP666 material. However, the PM-25-10L powered metal matrix composite material should perform well, even with short exposure to type IV shock-shock interactions.

\section{Acknowledgments:}

We would like to acknowledge the CFD work performed at CIAM by O. Gouskov and at NASA, through contracts with Analytical Services and Materials, NAS1-19864 by R. Hawkins, M. Mao, S. Srinivasan and D. Dilley; thermal analysis and engine cycle analysis through Lockheed Martin Engineering and Sciences, NAS1-19000, by P. Yarrington and Z. Pinckney respectively. In addition, special recognition to CIAM lead designer, M. Stokin, for development of modified scramjet design.

\section{References}

1. A. Roudakov, J. Schickman, V. Semenov, P. Novelli, O. Fourt: Flight testing an axisymmetrical scramjet - Russian recent advances. 44th Congress of the IAF. Oct. 1622, 1993. Graz, Austria.

2. A. Roudakov, V. Semenov and V. Kopehenov and J. Hick; Future Flight Test Plans of an Axisymmetric Hydrogen-Fueled Scramjet Engine on the Hypersonic Flying Laboratory. Presented at the 7th International Spaceplanes and Hypersonic Conference. AIAA Paper 96-4572, Nov. 1996

3. CIAM Staff; Characteristic features of the design and manufacture procedure of axisymmetrical scramjet for flight tests on HFTB "Kholod". CIAM Technical Report.

NASW4969, 1 Aug. 1996.
4. CIAM Technical Report, Feasibility determination of conducting hydrogen scramjet flight test with flight Mach number $\mathbf{M}_{\mathbf{f}}=7$ on hypersonic flying laboratory with rocket acceleration system (GASL contract N 4799), 23 Oct. 1993.

5. CIAM TR, Experimental scramjet for flight tests on HFL "KHOLOD" at flight Mach $\mathrm{M}_{\mathrm{f}}=6.5$. Preliminary choice and justification of engine configuration, design description. (NASA contract NASW- 4969), 17 Nov. 1994.

6. McGrory, W. D., Huebner, L. D., Slack, D. C, and Walters, R. W.: Development and application of GASP 2.0. AIAA Paper 92-5067, Dec. 1992.

7. Kamath, P., Mao, M.., and McClinton, C.: Scramjet combustor analysis with the SHIP 3-D PNS Code., AIAA paper 91-5090, Dec. 1991

8. Cubbage, J. M.: Effect of nose bluntness and controlled roughness on the flow on two hypersonic inlet center bodies without cowling at mach 5.98. NASA TN D-2900, July, 1965.

9. Rogers, R. C.: Mixing of hydrogen injected from multiple injectors normal to a supersonic airstream. NASA TN - D-6476, Sept. 1971.

10. Huber, P. W., Schexnayder, C. J. and McClinton, C. R.: Criteria for self-ignition of supersonic hydrogen-air mixtures. NASA TP1457 Aug. 1979.

11. McClinton, C. R.: Autoignition of Hydrogen injected transverse to a supersonic airstream. AIAA 79-1239, June 1979.

12. H. Inouye; Niobium in High temperature applications. Proceedings of the International Symposium, Niobium. The Metallurgical Society of AIME, San Francisco, CA., Nov. 8$11,1981$. 


\begin{tabular}{|c|c|c|c|c|c|c|c|c|c|c|}
\hline Material & Property & & \multicolumn{7}{|c|}{ Temperature, $\mathrm{K}$} \\
\hline & & & $300 \mathrm{~K}$ & 673 & 873 & 1073 & 1173 & 1273 & 1373 & 1673 \\
\hline $\mathrm{bpXUpT}$ & $\rho\left(\mathrm{Kg} / \mathrm{m}^{3}\right)$ & 8900 & & & & & & & & \\
\hline & $\lambda(\mathrm{w} / \mathrm{m} / \mathrm{K})$ & & 187 & 279 & 306 & & & & & \\
\hline & $\mathrm{c}(\mathrm{J} / \mathrm{Kg} / \mathrm{K})$ & & 360 & 406 & 406 & & & & & \\
\hline EP666 & $\rho\left(\mathrm{Kg} / \mathrm{m}^{3}\right)$ & 8110 & & & & & & & & \\
\hline & $\lambda(\mathrm{w} / \mathrm{m} / \mathrm{K})$ & & 14.5 & 14.5 & 18.9 & 22.0 & 23.5 & & & \\
\hline & $\mathrm{c}(\mathrm{J} / \mathrm{Kg} / \mathrm{K})$ & & 460 & 460 & 460 & 460 & 460 & & & \\
\hline PM-25-10L & $\rho\left(\mathrm{Kg} / \mathrm{m}^{3}\right)$ & 8100 & & & & & & & & \\
\hline & $\lambda(\mathrm{w} / \mathrm{m} / \mathrm{K})$ & & 10.9 & 16.9 & 19.8 & 22.6 & & 25.5 & & 30 \\
\hline & $\mathrm{c}(\mathrm{J} / \mathrm{Kg} / \mathrm{K})$ & & 450 & 580 & 630 & 700 & & 750 & 770 & \\
\hline
\end{tabular}

Table 1. Material Thermal Conductivity $\lambda$, Heat Capacity $c$, and Density $p$.

\begin{tabular}{|l|c|c|}
\hline Parameters & $\begin{array}{c}\text { NASA } \\
\text { Predictions }\end{array}$ & $\begin{array}{c}\text { CIAM } \\
\text { Predictions }\end{array}$ \\
\hline $\mathrm{m}, \mathrm{kg} / \mathrm{sec}$ & 2.70 & 2.70 \\
\hline $\mathrm{p}_{2}, \mathrm{~Pa}$ & 40000 & 39000 \\
\hline $\mathrm{M}_{2}$ & 3.2 & 3.15 \\
\hline $\mathrm{P}_{\mathrm{t}, 2} / \mathrm{P}_{\mathrm{t}, 0}$ & 0.361 & 0.31 \\
\hline $\mathrm{P}_{2} / \mathrm{P}_{0}$ & 17.905 & 17.8 \\
\hline$\eta_{\mathrm{KE}, 1}$ & 0.967 & \\
\hline$\eta_{\mathrm{KE}, 2}$ & 0.947 & \\
\hline $\mathrm{T}_{2}, \mathrm{~K}$ & 651 & \\
\hline$\eta_{\mathrm{KE}, \mathrm{Adia}, 1}$ & 0.975 & \\
\hline $\mathrm{H}_{\mathrm{t}, 2} / \mathrm{H}_{\mathrm{t}, 0}$ & 0.985 & \\
\hline$\eta_{\mathrm{KE}, \mathrm{Adia}, 2}$ & 0.963 & \\
\hline
\end{tabular}

Table 2. Inlet performance summary. 


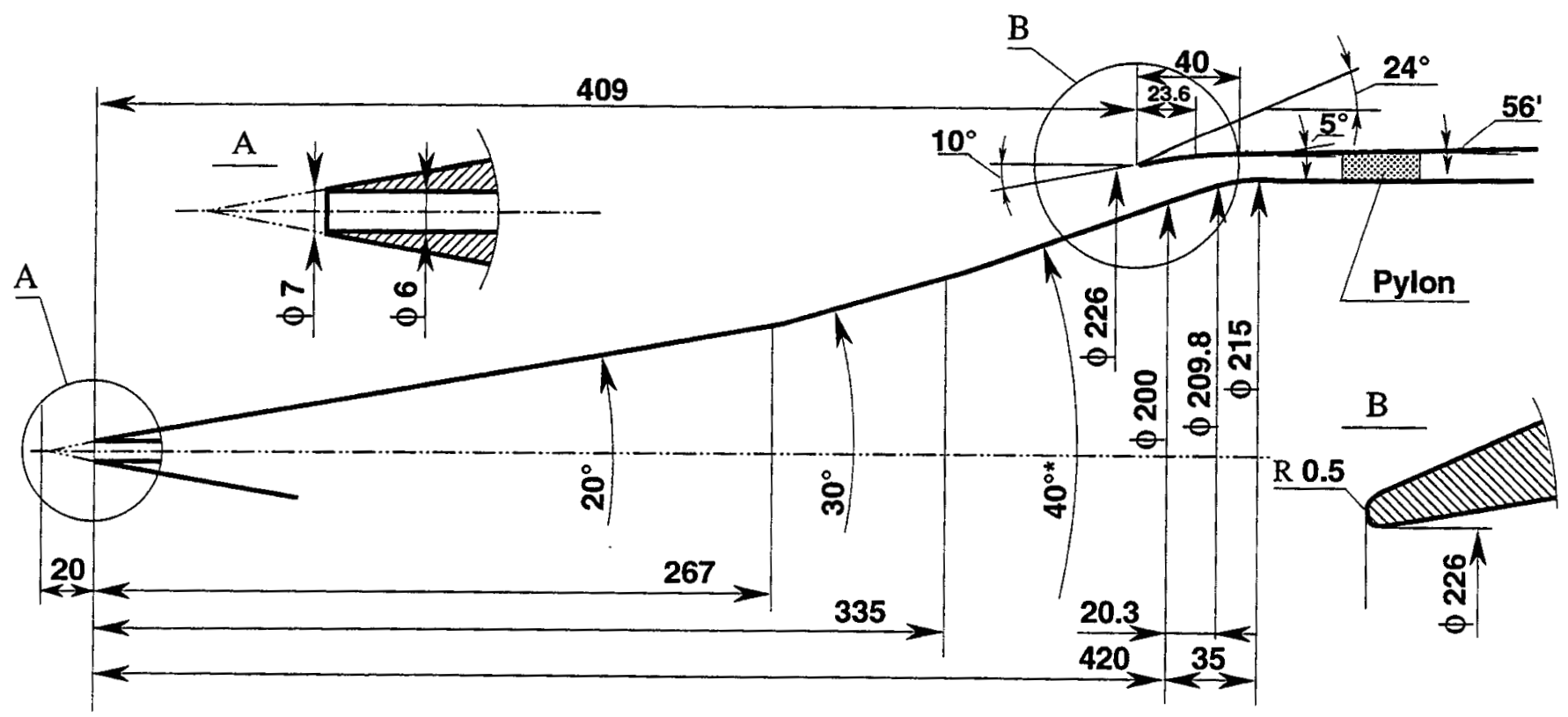

a. Inlet details.
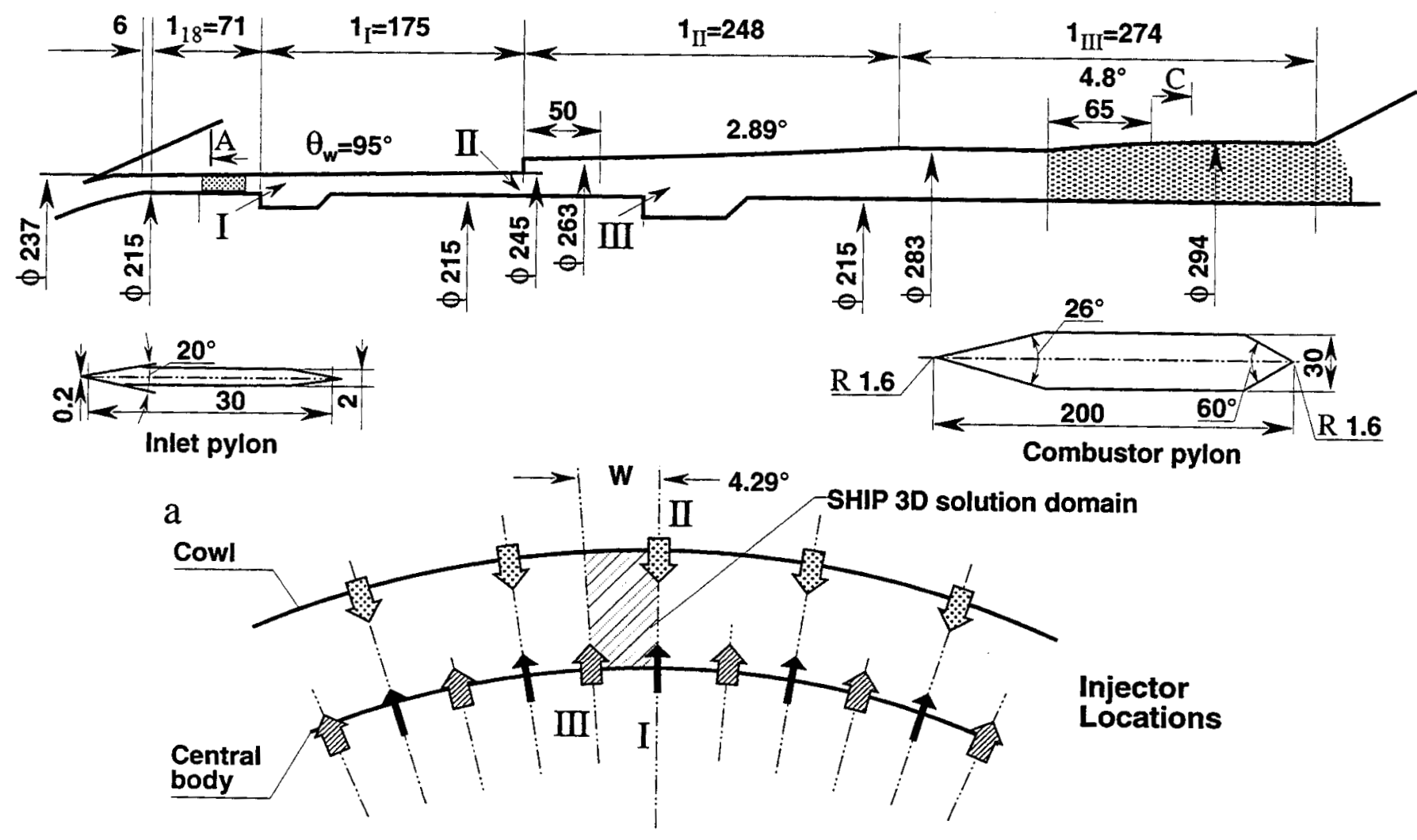

b. Combustor details.

Figure 1. Inlet and combustor geometry details of scramjet engine (units, $m m$; $\phi$ signifies diam.). 


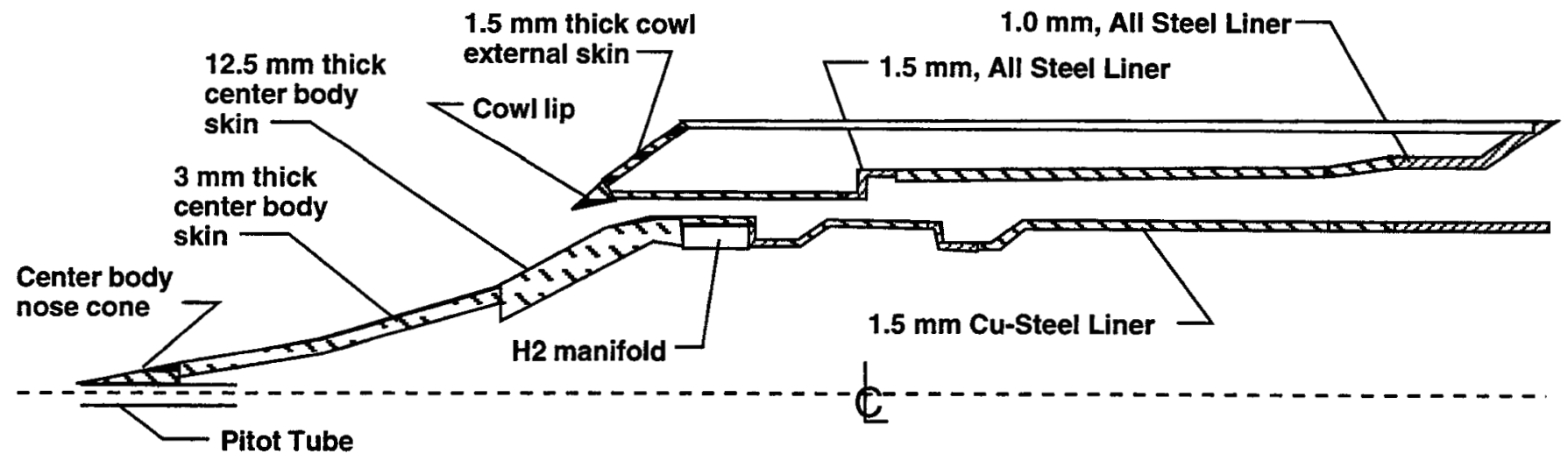

Figure 2. Scramjet engine structural and material details.

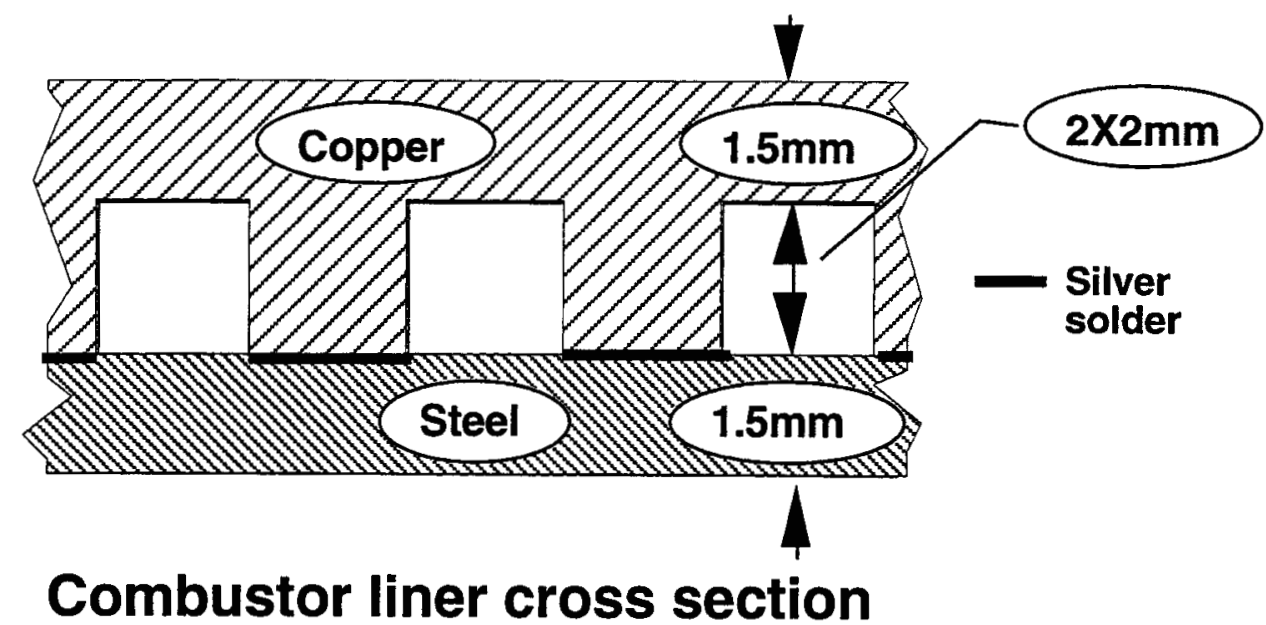

Figure 3. Typical cooling liner design features.

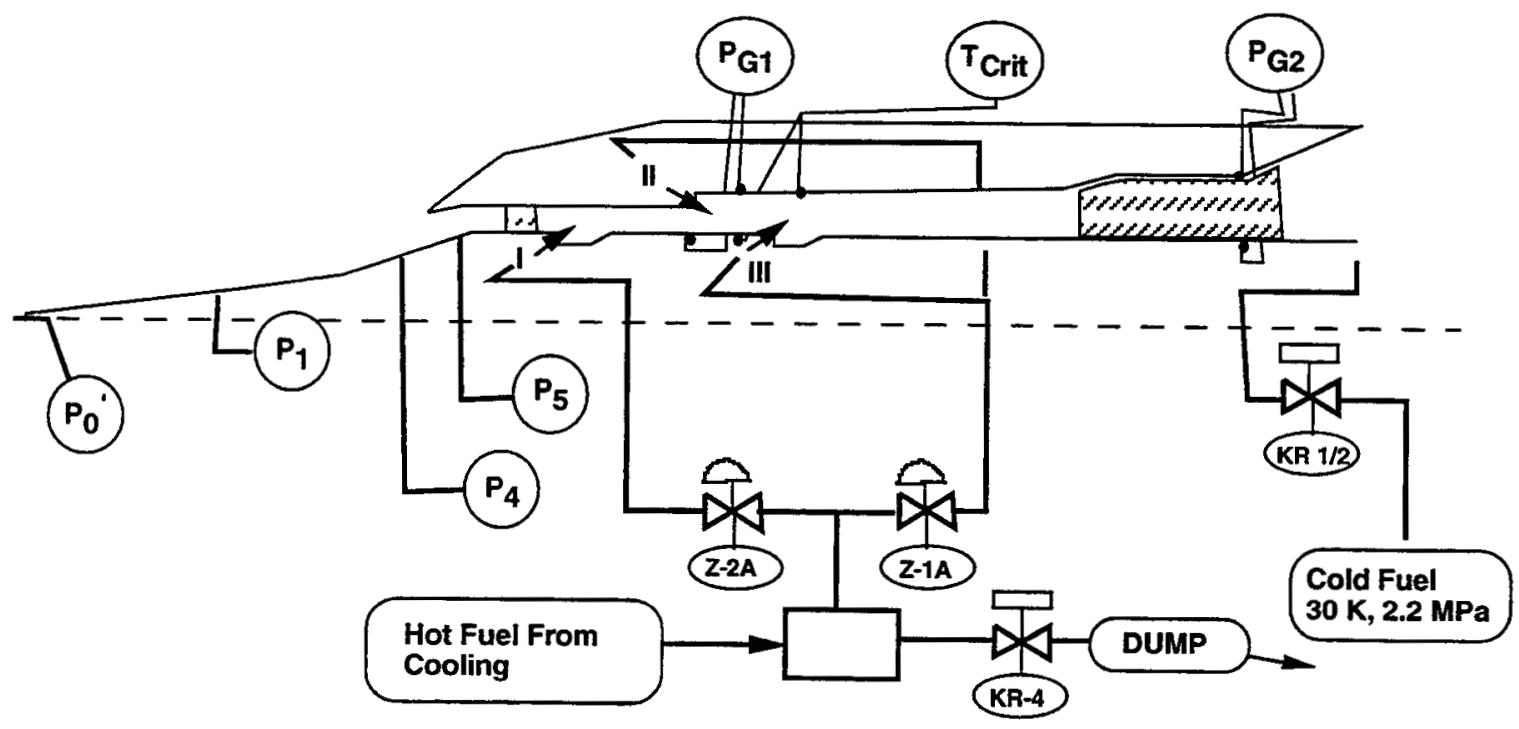

Figure 4. Fuel coolant control system. 


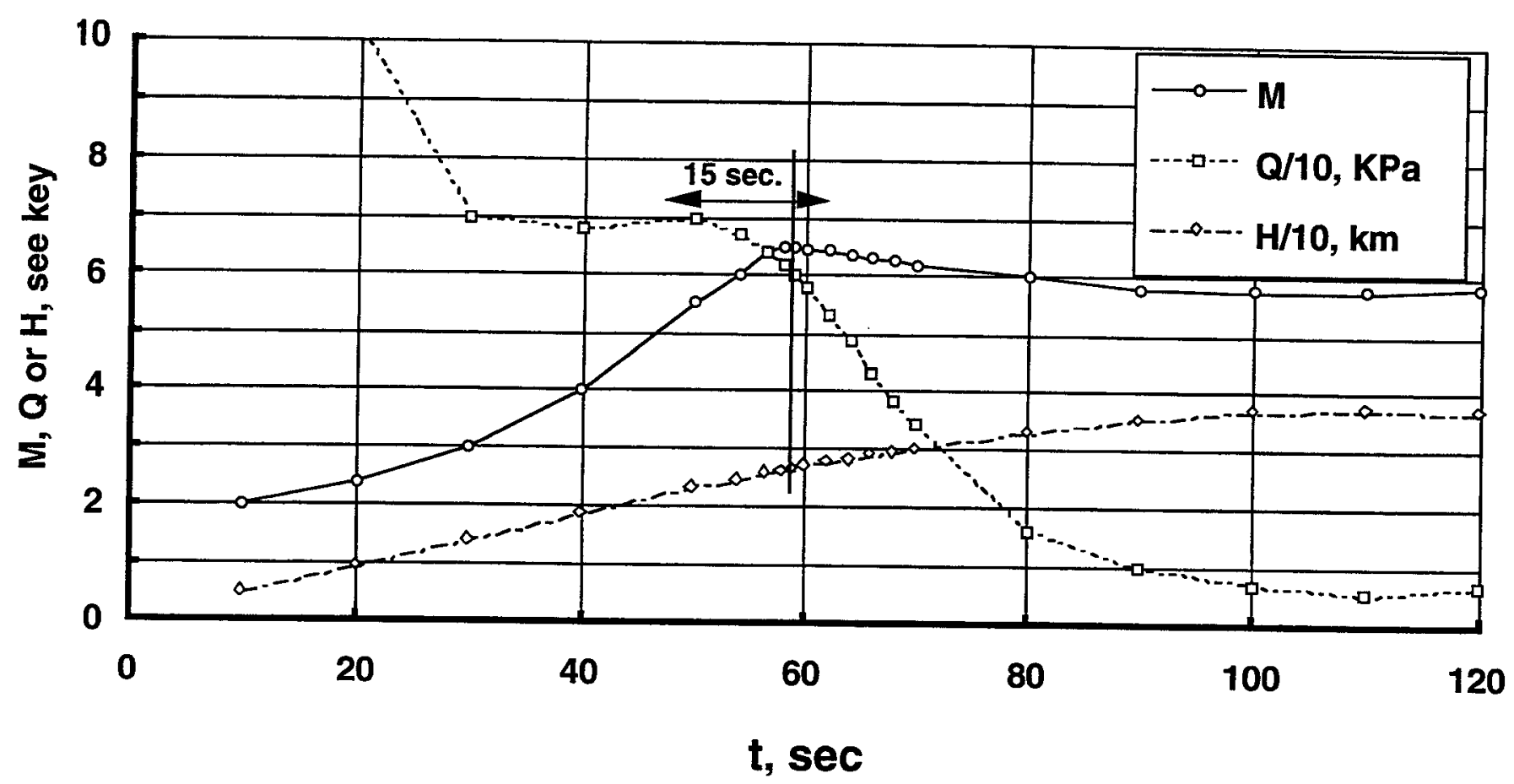

Figure 5. Flight trajectory.

(0)

External Inlet (1)

\begin{tabular}{|c|} 
External Inlet \\
GASP \\
External/Internal Inlet
\end{tabular}

CIAM

Implicit Godunav (2nd order) Baldwin-Lomax turbulence model Blunt cneterbody, sharp cowl Axisymmetric

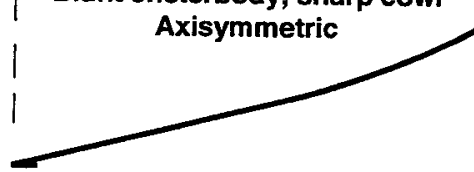

(1)
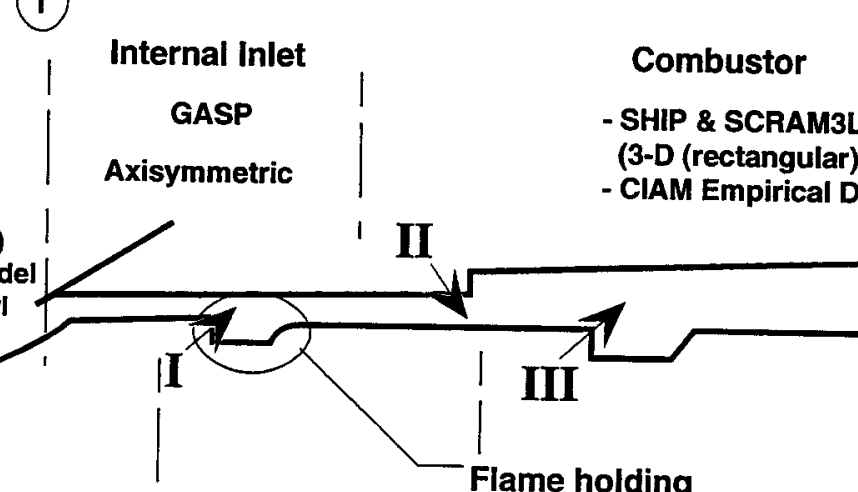

(2) Isolator

1 II
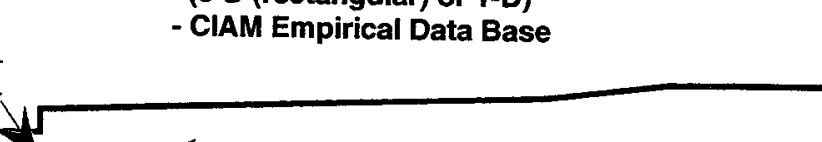

\section{SCRAM3L}

Finite-rate chemical kinetics

2-D and 3-D FNS

Finite rate chemical kinetics

Baldwin-Lomax turbulence model

(K- $\varepsilon$ for combustor modeling)

\section{III}

Flame holding

GASP

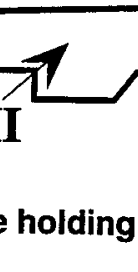

3-D PNS

Complete reaction model q- $\omega$ turbulence model

Figure 6. Flowpath analysis methodology. 

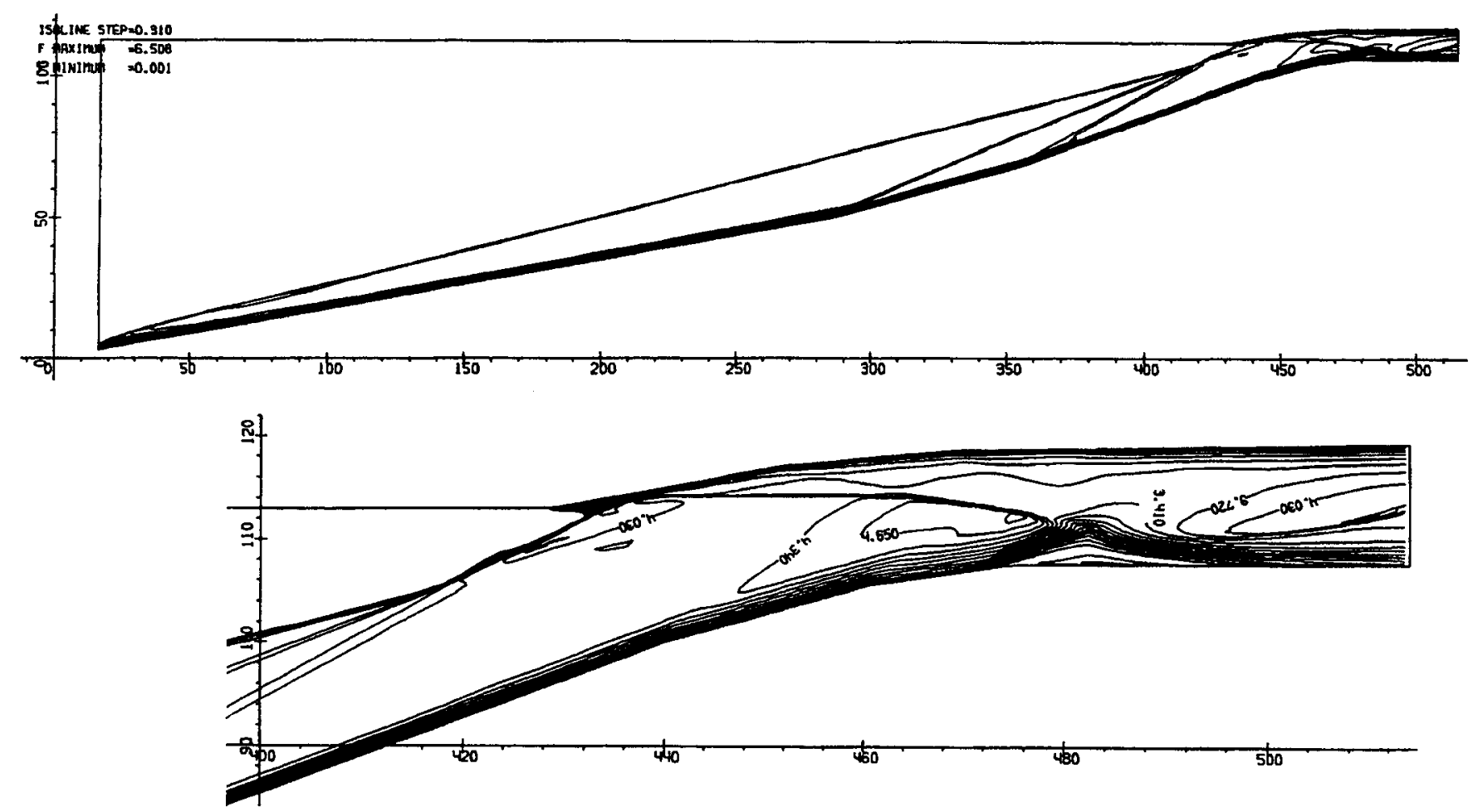

a. Results from analysis by CIAM (adaptive grid).

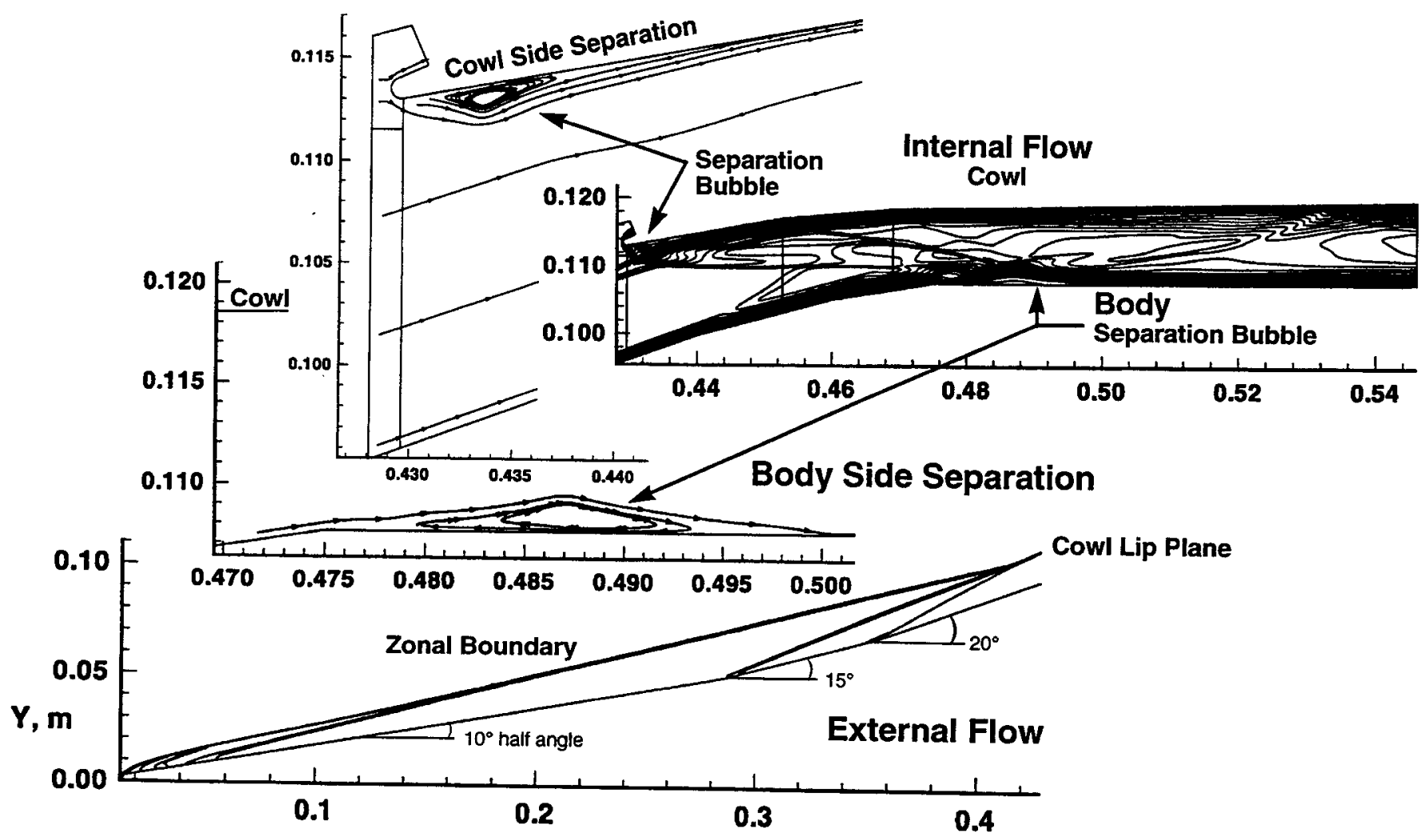

b. Results from analysis by NASA.

Figure 7. Inlet Mach number contours. 


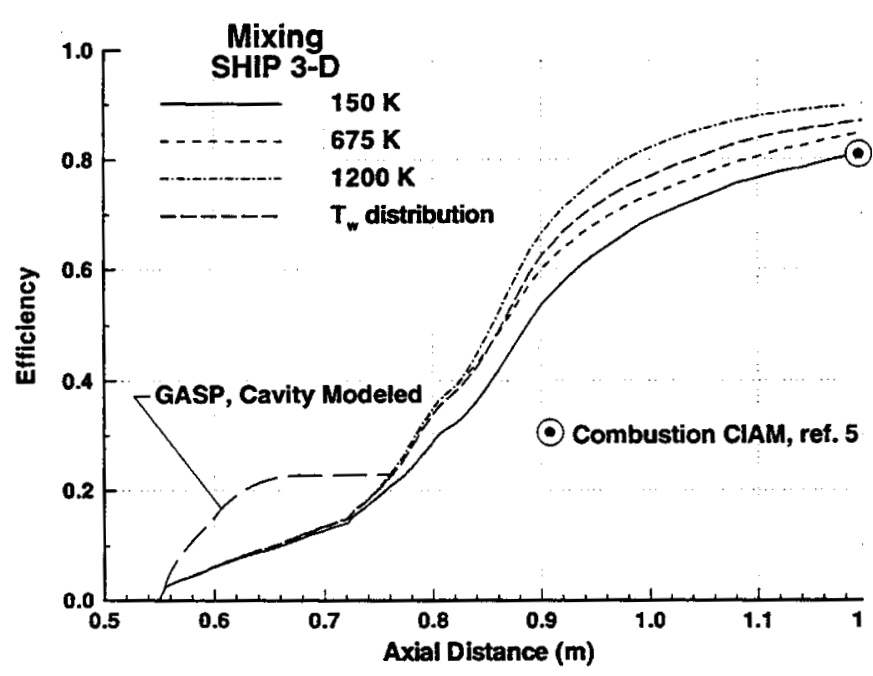

Figure 8. Predicted fuel mixing.

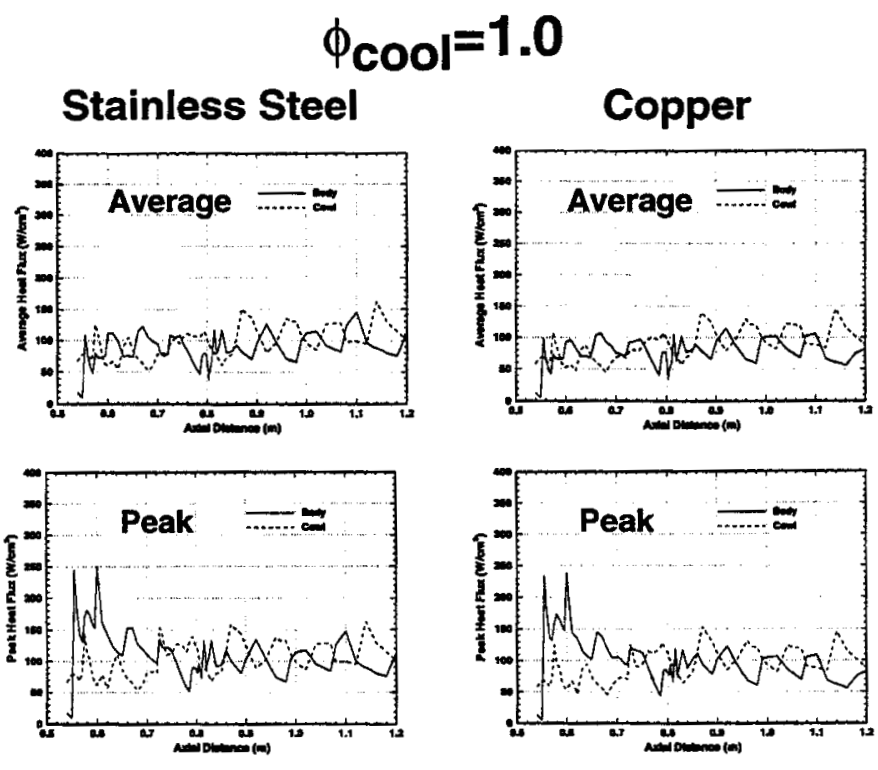

Figure 9. Predicted combustor heat flux; peak and average, variable wall temperature.

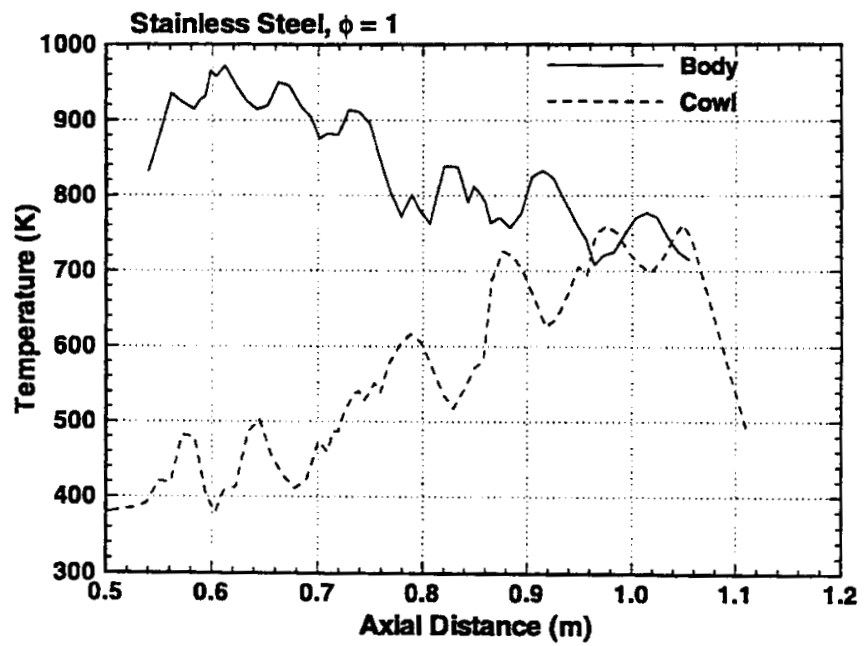

Figure 10. Combustor wall temperature. Stainless steel heat exchanger.

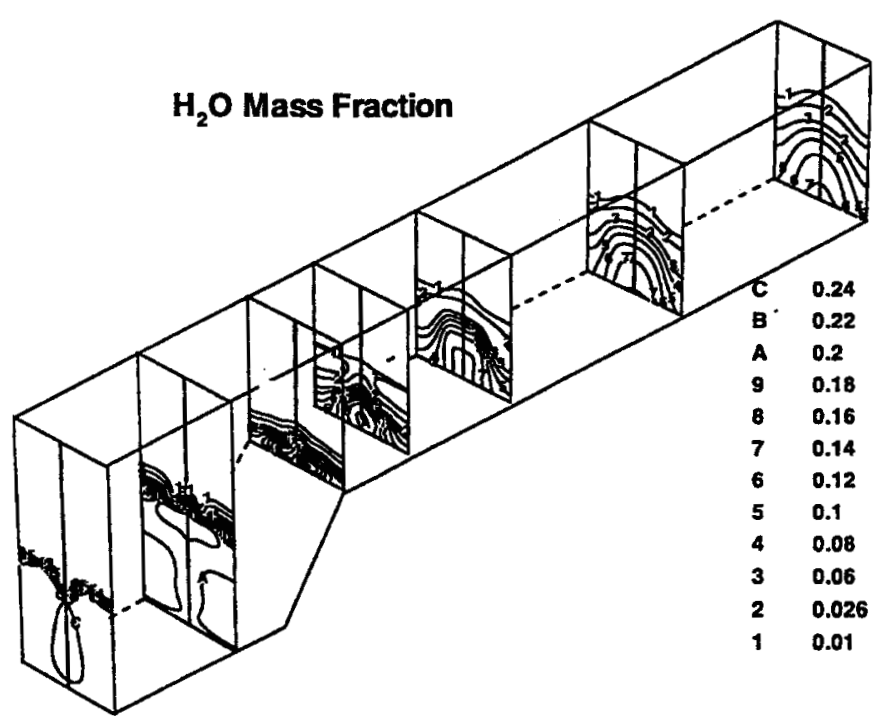

Figure 11. Water mass fraction from GASP Cavity I solution. 


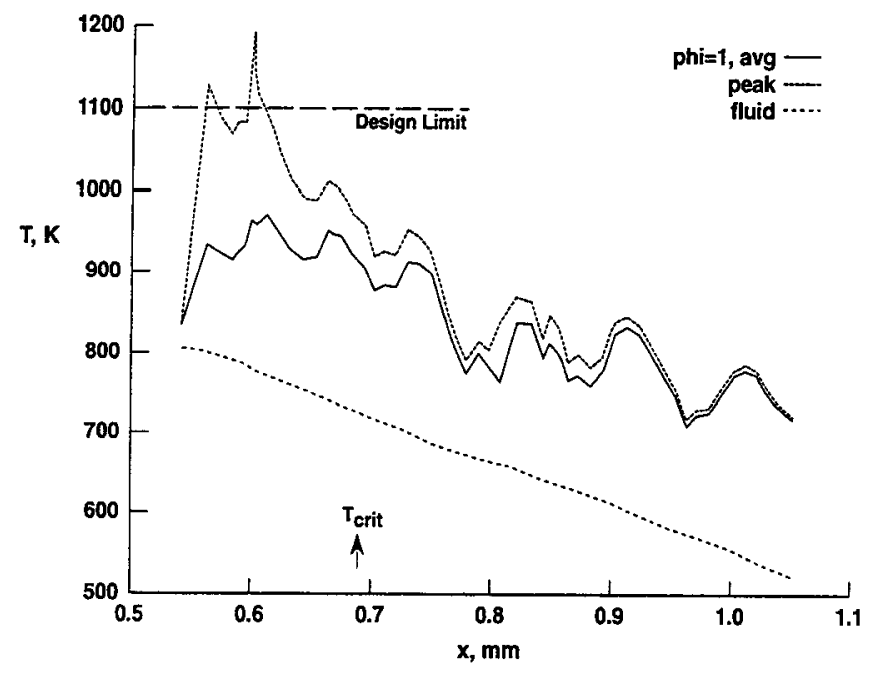

Figure 12. Wall temperature distribution (body sidesteel heat exchanger).

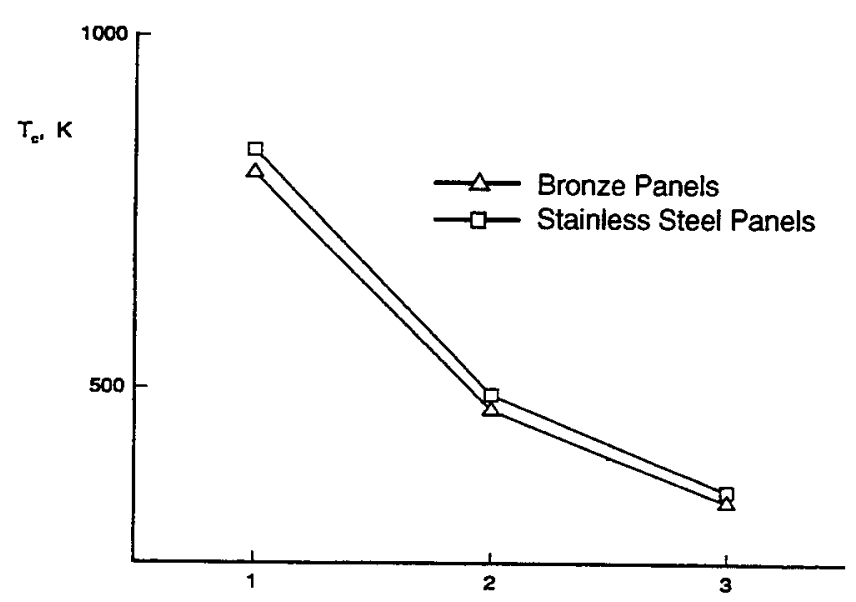

Figure 13b. Coolant exit temperature.

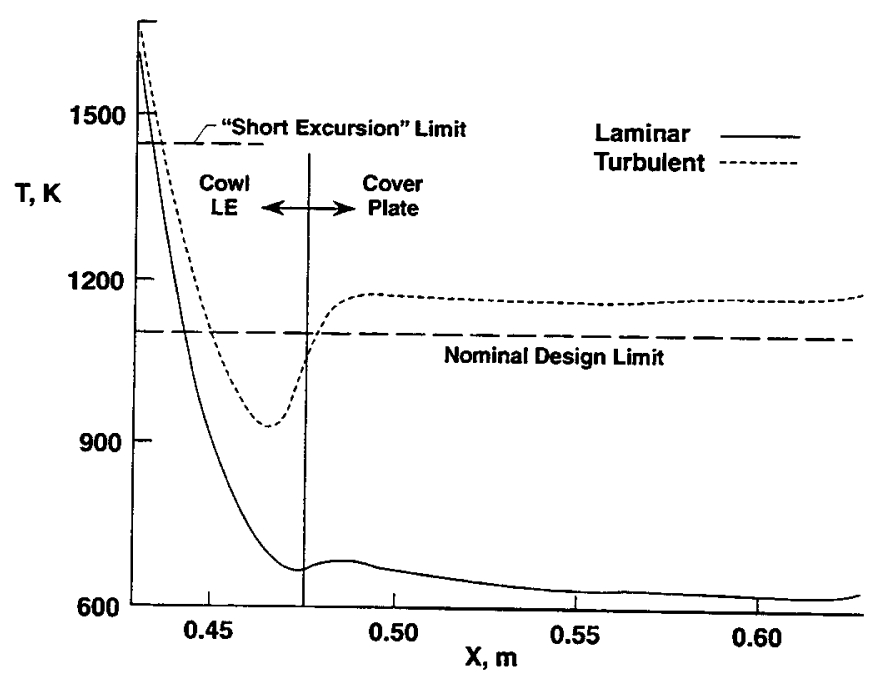

Figure 15. Cowl external surface temperature (15 seconds exposure to $M 6.5, h=28 \mathrm{~km}$ ).

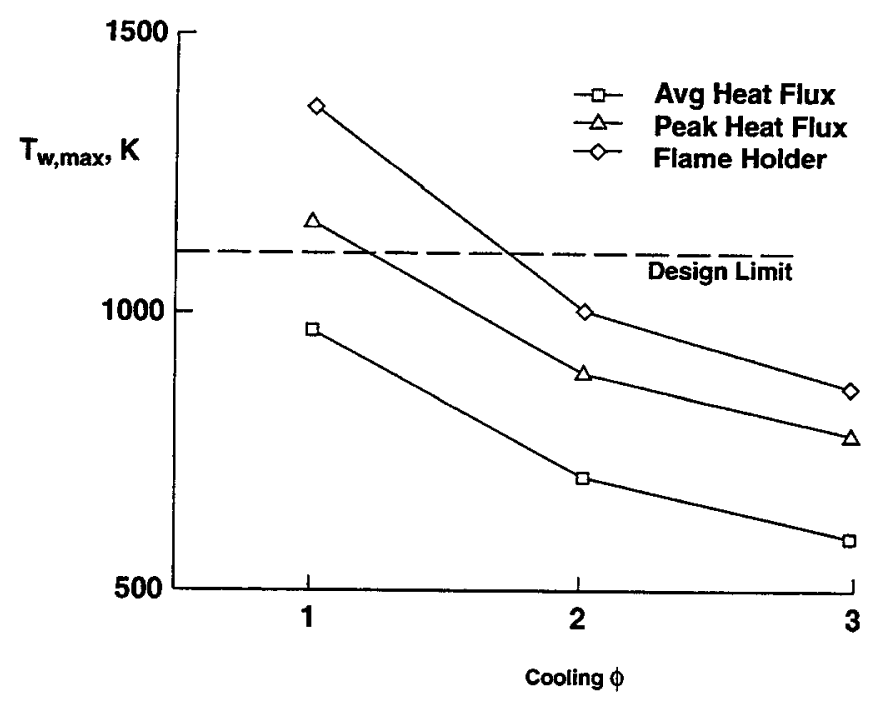

Figure 13a. Combustor maximum wall temperature.

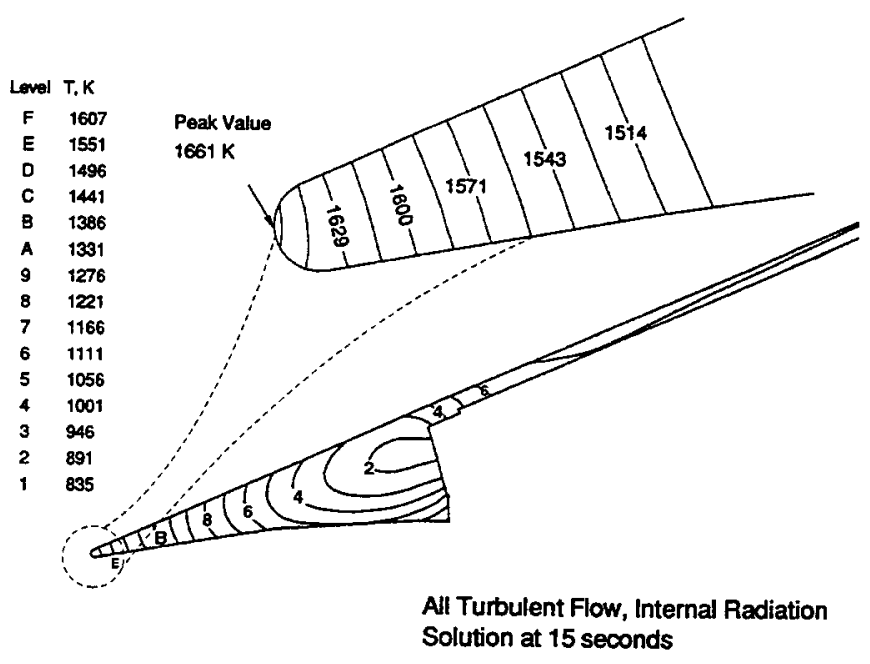

Figure 14. Cowl leading edge temperature.

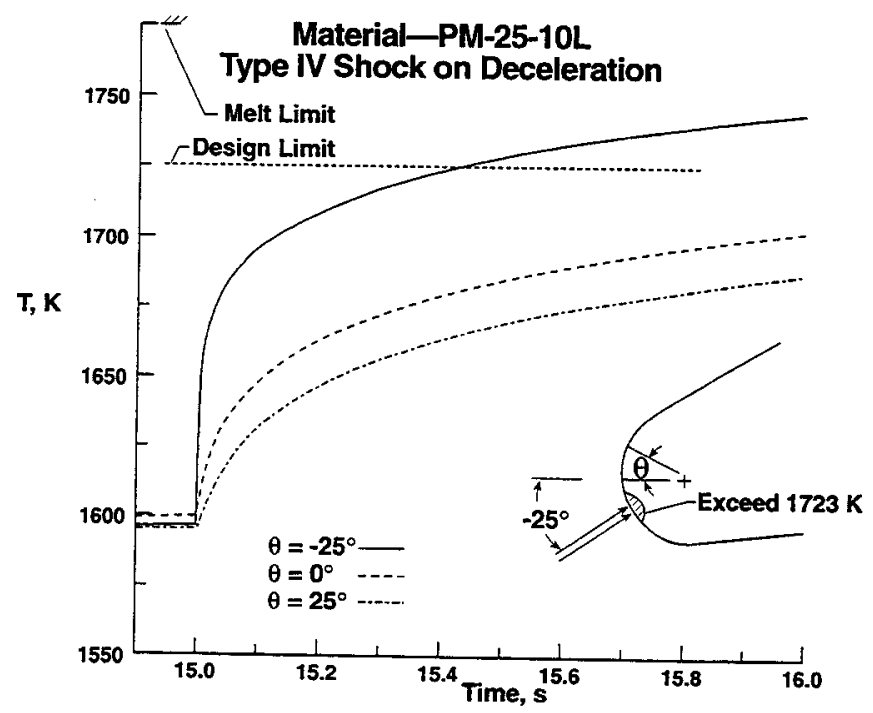

Figure 16. External surface temperature for Type IV shock interaction. 